\title{
Xanthoma of Bone: A Mini Review
}

Ghalib Alhaneedi ${ }^{1^{*}}$, Motasem Salameh ${ }^{1}$ and Hasan AbuHejleh ${ }^{2}$

${ }^{1}$ Department of Orthopedic Surgery, Hamad Medical Corporation, Alrayan Street, Doha, Qatar

${ }^{2}$ Department of Orthopedic Surgery, Hamad General Hospital, Alrayan Street, Doha, Qatar

*Corresponding author: Ghalib Alhaneedi, Department of Orthopedic Surgery, Senior Consultant Orthopedic Surgeon, Hamad Medical Corporation, Alrayan Street, Doha, Qatar, Tel: 0097455975125; E-mail: ghaliboudah@yahoo.com

Received date: Nov 09, 2017; Accepted date: Jan 2, 2018; Published date: Jan 9, 2018

Copyright: ( 2017 Alhaneedi G, et al. This is an open-access article distributed under the terms of the Creative Commons Attribution License, which permits unrestricted use, distribution, and reproduction in any medium, provided the original author and source are credited.

\begin{abstract}
Xanthoma of bone is a rare benign primary bone disorder with a hallmark of cholesterol deposition in the bone frequently seen in men and in patients over 20 years of age. This mini review provides an overview of the known clinical, radiological and pathological features of the disease which can mimic primary bone tumors or metastatic lesions. In this review, we focus on the current considerations in the use of clinical and radiological features, lipid profile and histopathological study for the definitive diagnosis. Despite this wealth of features, the definitive diagnosis of bone xanthoma continues to be difficult. The current status of biopsy technique, treatment, outcome and prognosis of bone xanthoma are also reviewed, highlighting recent successes and ongoing challenges. The review is concluded with the recommendations of the Evidence-Based Management of bone xanthoma. Despite improvements in imaging, biopsy technique and the delivery of treatment, the diagnosis has remained challenging for orthopedic surgeons to differentiate it from other bone benign and aggressive lesions.
\end{abstract}

Keywords: Xanthoma; Bone; MRI; CT; Skeletal; Hyperlipidemia

\section{History}

The word Xanthoma is derived from the Greek "Xanthos" meaning yellow. It is a benign lesion developing due to abnormal deposition of cholesterol in various human connective tissues. Commonly found in the skin around the eyes (Xanthelasma), over the joints (Xanthoma tuberosum), in the tendons of the extremities (Xanthoma tendinosum). Xanthomas of skeleton are rare but still important; due to features mimicking bone tumors and definitive diagnosis before the surgery is very difficult [1-3].

\section{Introduction}

Bone xanthoma is a rare disorder typically occurs in the setting of endocrine or metabolic diseases with increased cholesterol levels, especially primary hyperlipidemia, hypolipoproteinemia Type II \& III, diabetes mellitus, hypothyroidism and lipoprotein lipase deficiency, hence it is called secondary bone xanthoma [4-7]. It is also reported in non-hyperlipidemic states and it is called primary bone xanthoma $[1,6-8]$. Xanthomatous changes of the bone is reported in various bone lesions e.g. fibrous dysplasia, giant cell tumor, aneurysmal bone cysts, simple bone cyst non-ossified fibroma, chondroblastoma, fibrous histiocytoma, histiocytosis $\mathrm{X}$ and chronic osteomyelitis [2,4,5].

Bone xanthomas are solitary lesions, rarely multiple. More common in males with male-to-female ratio of 2:1. The condition can be seen at any age, but the incidence is highest in the $3 \mathrm{rd}$ and 4 th decades of life and infrequently diagnosed in pediatrics age groups $[1,4,6]$. Bone Xanthomas occur commonly on flat and cancellous bone and rarely on cortical bone, however, no bone is spared and the lesions can occur anywhere in the appendicular and axial skeleton. Very rarely they break the cortex and extend into the surrounding soft tissues. The size of the lesion is usually between $2-5 \mathrm{~cm}[1,8-11]$.

\section{Anatomic Distribution}

With respect to its anatomic distribution most of the lesions are solitary usually occurring in the appendicular skeleton rather than the axial skeleton. The most frequent sites of involvement are skull, pelvis, mandible, sacrum, ribs, calcaneus, hand, ulna, radius, humerus, femur, spine and tibia $[2-4,7,11-15]$.

\section{Pathogenesis}

The possible proposed pathogenesis of bone xanthomas may be due to leakage of the lipids and cholesterol at the site of the lesion which attract macrophages. These macrophages engulf the lipids and cholesterol and look like typical foamy cells seen on histopathology [6-8]. Minor trauma or preexisting bony lesion may be triggering factors to the development of these lesions. When xanthomatous changes occur on a preexisting bony lesion such as simple bone cyst, aneurismal bone cyst, fibrous dysplasia and some malignant tumors are called xanthomatous variant. Such xanthomatous changes are usually confined to certain of the whole lesion suggesting degenerative nature. Therefore, it is essential to examine the whole biopsy material microscopically in order to avoid erroneous diagnosis on histopathology $[1,4,6,13]$.

\section{Classification}

Classification of xanthoma may be helpful in the processes of diagnosis and treatment: $[4,10,16]$.

1. Xanthomatous variant: xanthomatous changes in advanced stage of skeletal benign or malignant pre-existing lesions;

2. Secondary xanthoma: forms in the skeletal system in patients with disturbed lipid metabolism mainly type-2 and 3 hyperlipidemia patients;

3. Primary xanthoma with normal lipid metabolism. 
Page 2 of 4

\section{Diagnostic Workup}

The most frequent presenting symptom is pain, sometimes discovered incidentally from imaging studies taken for other reasons. In addition, the lesion can present as a pathological fracture $[1,4,6-8,11]$.

\section{Imaging Features}

Radiographs of bone xanthoma usually show a small, wellcircumscribed, purely osteolytic lesion, often accompanied by a surrounding rim of sclerosis with a narrow zone of transition. Rarely, lesions can have an aggressive appearance with a wide zone of transition and may be multifocal. Cortical expansion can be observed in some cases. However, intra-lesion calcification, cortical destruction and soft-tissue extension is absent (Figure 1) $[4,8,12,13]$.

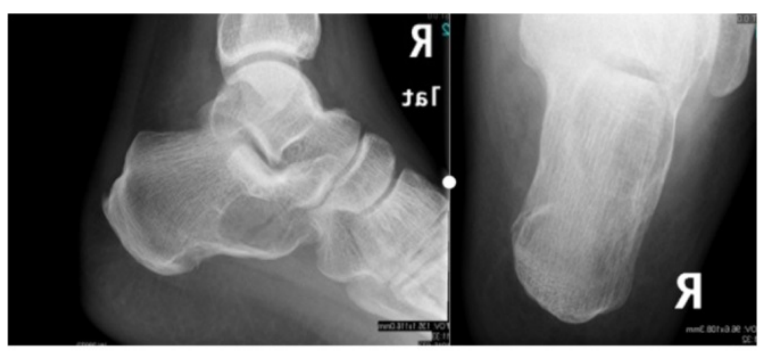

Figure 1: Calcaneus lateral and axial X-rays.

CT scans of bone xanthoma show loss of a normal trabecular pattern in the medullary cavity, and the density is higher than that of the normal bone $[4,13]$.

MRI is typically characterized by a circumscribed area of low and high signal intensity on T1 and T2 weighted images respectively and associated low intensity areas on fat suppressed images which is hypothesized to result from the cholesterol-laden histiocytes seen on histopathology (Figure 2) [4,12].

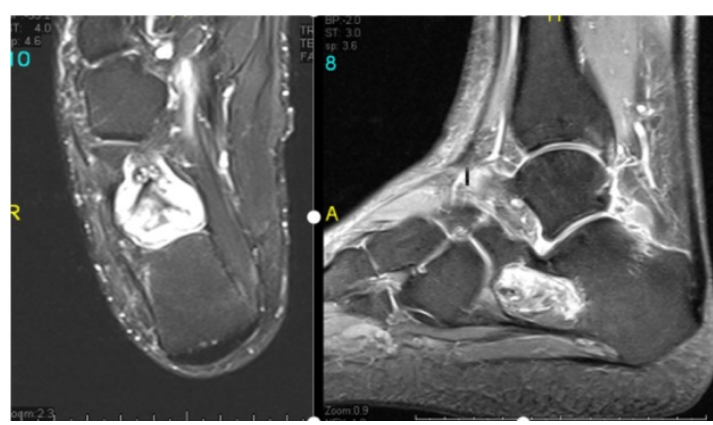

Figure 2: Calcaneus MRI images.

Whole body bone scintigraphy typically shows increased uptake of (Tc-99 m MDP4). Bone Scintigraphy allows for mapping of lesions and post-therapy follow up and multifocal lesions that are not radiographically visible may be detected $[7,8,12]$.

\section{Histopathologic Features}

The Biopsy is usually essential for histopathological diagnosis of bone xanthoma $[4,8,12,13]$. Grossly appears as localized enlargement of the bone, and the lesion is solid, granular, and dull yellow. Sometimes the lesions can be cystic with fluid and yellow granular material $[1,7]$.

Histologically, the typical appearance is a lesion consisting of sheets of foam cells and occasional non-foamy mononuclear or multinucleated giant cells. Occasionally, the Touton-type giant cells are identified. There are cholesterol clefts and giant cells around them in focal areas. Usually these are closely intermingled although one of the features sometimes predominated. The nuclei are small and generally eccentrically situated (Figure 3) $[8,11,13]$.

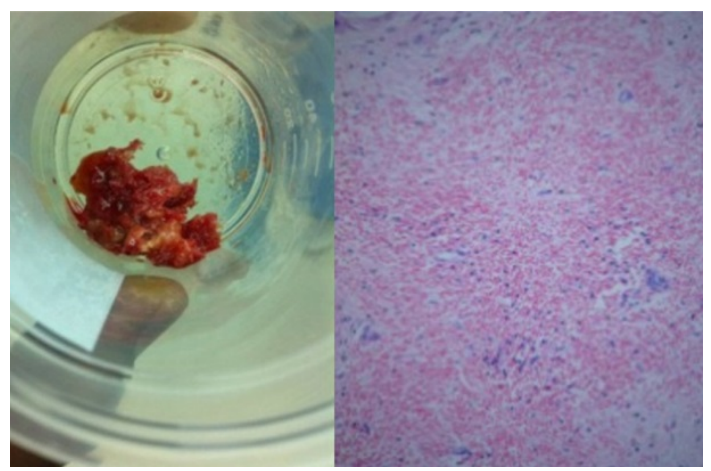

Figure 3: Histopathology images of bone xanthoma with abundant cholesterol clefts, giant cells and sheets of foamy macrophages [4].

The lesion has histological similarities to pigmented villonodular synovitis, but it is not located in synovial lined tissues $[1,7,8,11,13]$.

\section{Differential Diagnosis}

The differential diagnosis of the bone xanthoma depends on clinical and radiological findings and on the histologic identification of diagnostic areas. The differential diagnoses include solitary bone cyst, intraosseous lipoma, osteoblastoma, Erdheim-Chester disease, brown tumor of hyperparathyroidism, giant cell tumor and chordoma. It is important especially in a patient above 40 years not be mistakenly diagnosed as a metastatic clear cell carcinoma and multiple myeloma $[8,10,12,13,17]$.

\section{Treatment and Prognosis}

The treatment of bone xanthoma is either medical by observation and treatment of the underlying hyperlipidemia or surgical by curettage and bone grafting. Primary bone Xanthomas are benign, once a biopsy has confirmed the presence of xanthoma, the optimal treatment typically consists of curettage of the lesion and bone grafting which is effective and curative $[1,2,4,7,11-14,16]$.

The necessity of prophylactic internal fixation and protection of the extremity from full weight bearing depends on the location and extent of the lesion. Because the pelvis, proximal femur, and tibia are particularly prone to pathologic fracture hence, internal fixation may be indicated. Adjuvant radiotherapy may be indicated when curettage is incomplete or difficult to achieve, as in the skull base or spine 
Page 3 of 4

$[8,11,12,14]$. Management of the patient's Dyslipidemia with diet, lifestyle modification and drug therapy may cause regression of the secondary bone xanthoma [6-8].

\section{Prognosis}

The prognosis is good after treatment of bone xanthoma $[1,4-6,8,9,11]$.

\section{Discussion}

Bone xanthomas are rare, non-neoplastic disorders presenting diagnostic dilemma to orthopedic surgeons as their clinical and radiological features can resemble bone tumors. When bone xanthomas occur without any underlying cause and the patient have normal lipid levels they are called primary xanthoma $[1,4,13]$.

Primary xanthomas of bone more often involve the flat bones than the long bones with the mandible, temporal bone, ribs, and pelvic bones being most commonly involved by the condition $[4,5,14,15]$. In secondary type, the bone xanthoma may be the first sign of hyperlipidemia and hyperlipidemia may develop years after the appearance of xanthoma, hence, the term primary bone xanthoma should be used very carefully $[1,4,13]$.

Bertoni et al. [13] defined primary bone xanthoma as a condition in which the xanthomatous pattern is extensive and when it is not confirmed as secondary phenomenon on pre-existing lesion. Some authors define this lesion as a variant, because xanthoma and giant cells may be seen in many non-neoplastic and neoplastic lesions of the bone $[4,13]$.

Bertoni et al. [13] reported 21 cases of primary xanthoma of bone in normolipidemic patients. With 20 patients over 20 years of age and male-to-female ration of 2:1. Most of the cases were solitary with predominance to pelvic bones, ribs and skull. Harsanyi and Larsson [18] described seven cases of xanthomatous lesions in the mandible, 6 females and 1 male with average age of 24 years. Other reported cases and series are illustrated in Table 1.

\begin{tabular}{|c|c|c|c|c|c|c|c|}
\hline Authors & $\begin{array}{l}\text { Number of } \\
\text { Cases }\end{array}$ & Age & Sex & Site & $\begin{array}{l}\text { Multiple or } \\
\text { single }\end{array}$ & Type & Treatment \\
\hline Dalinka et al. [19] & 1 & 55 & Male & Ribs & Multiple & Secondary & Conservative \\
\hline Jackler et al. $[20,21]$ & 1 & NA & NA & Skull & Single & Secondary & Surgical debulking and medical \\
\hline Robertson et al. $[22,23]$ & 1 & 39 & Male & $\begin{array}{l}\text { Thoracic } \\
\text { vertebra }\end{array}$ & Single & Primary & Resection and posterior instrumentation \\
\hline Kinberg et al. [22] & 1 & 19 & Male & Calcaneus & Single & Primary & Curettage and Cementing \\
\hline Kuroiwa et al. [20] & 1 & 62 & Female & Skull & Single & Secondary & Total resection and cranioplasty \\
\hline Yamamoto et al. [10] & 1 & 51 & Female & Calcaneus & Single & Primary & Curettage and Cementing \\
\hline \multirow{3}{*}{ Alden et al. [11] } & \multirow{3}{*}{3} & 44 & Male & Tibia & Single & Primary & Curettage, grafting and internal fixation \\
\hline & & 23 & Male & Pelvis & Single & Primary & Curettage and grafting \\
\hline & & 9 & Male & Skull & Single & & curettage and cranioplasty \\
\hline Kaddour et al. [15] & 1 & 45 & Male & Rib & Single & Primary & Resection \\
\hline Torigoe et al. [16] & 1 & 44 & Female & $\begin{array}{l}\text { Humerus, } \\
\text { Femur }\end{array}$ & Multiple & Secondary & Medical \\
\hline Kapukaya et al. [23] & 1 & 22 & Male & Calcaneus & Single & Primary & Curettage and Grafting \\
\hline Mohan et al. [9] & 1 & 37 & Male & Hand & Single & Primary & Curettage \\
\hline Asano et al. [17] & 1 & 24 & Female & Skull & Single & Primary & Neuronavigation Resection \\
\hline Ali et al. [8] & 1 & NA & Female & $\begin{array}{l}\text { Bilateral } \\
\text { humerus }\end{array}$ & Multiple & secondary & $\begin{array}{l}\text { resection and reconstruction with } \\
\text { endoprosthesis }\end{array}$ \\
\hline Yaligod et al. [1] & 1 & 45 & Female & Distal ulna & Single & Primary & Curettage and grafting \\
\hline Ahmed et al. [4] & 1 & 50 & Male & Calcaneus & Single & Primary & Curettage and Cementing \\
\hline Kumar et al. [12] & 1 & 51 & Male & Radius & Single & Primary & Curettage and Cementing \\
\hline Shin et al. [14] & 1 & 25 & Female & Femur & Single & Primary & Curettage and grafting \\
\hline
\end{tabular}

Table 1: Case reports and case series of bone Xanthomas.

To avoid an erroneous diagnosis, the radiological features of the lesion should be studied properly, all biopsy material examined microscopically and lipid profile should be investigated to differentiate between primary and secondary xanthoma. Primary xanthoma may be 
treated with curettage and bone graft while secondary xanthoma is treated non-surgically in which the skeletal manifestations would disappear with systemic treatment of hyperlipidemia $[4,10]$.

\section{Current Recommendation}

Presently, patients who present with xanthoma of bone should undergo confirmation of diagnosis with radiograph, CT, MRI, biopsy and assessment of the lipid profile. Other differential diagnosis should be ruled out followed by treatment in form of medical or surgical modalities.

\section{Conclusion}

Bone xanthoma present a unique challenge to orthopedic surgeons for diagnosis using only clinical and imaging techniques. Detailed histopathological examination is essential to establish the diagnosis. Despite improvements in imaging, biopsy technique, and the delivery of treatment, the diagnosis has remained challenging to differentiate it from other aggressive lesions. As the prognosis of bone xanthoma is excellent, primary bone xanthoma may be treated with curettage and bone graft while secondary xanthoma is treated non-surgically in which the skeletal manifestations will disappear with systemic treatment of hyperlipidemia.

\section{Acknowledgement}

I acknowledge the contribution of Dr. Hasan Abuhajelah and Dr. Motasem Haroun for this Mini Review.

\section{Conflict of Interest}

Authors disclosed no conflict of interest.

\section{References}

1. Yaligod V, MaheshS, Rudrappa G, Choudhary L (2013) Xanthoma of ulna. J Evol Med Dent Sci 2 Issue: 6691-6695.

2. Chakravarthi V, Aruna E, Chandra Raao DN, Ranga Rao D (2012) Bilateral Tibia Xanthoma in a Normolipidemic Patient-Report of a Rare Case with Review of Literature. Int J Clin Med 3: 234-237.

3. Dallari D, Marinelli A, Pellacani A, Valeriani L, Lesi C, et al. (2003) Xanthoma of Bone: First Sign of Hyperlipidemia Type IIB: A Case Report. Clin Orthop Relat Res 410: 274- 277.

4. Ahmed G, Al Dosari M, El-Mahi M, Abolfotouh S (2014) Primary xanthoma of calcaneus bone: Case report. Int J Surg Case Rep 5: 699-702.
5. Wang Z, Wei Z, Huang L, Ke1Z, Luo C, et al. (2014) Primary nonhyperlipidemia xanthoma of bone: a case report with review of the literature. Int J Clin Exp Med 7: 4503-4508.

6. Guerrouj H, Mouaden A, BenRais N (2012) Xanthoma of Bone: A Case Report. Case Rep Endocrinol.

7. Ali S, Fedenko A, Matcuk G, Patel D, Gottsegen C, et al. (2013) Bilateral primary xanthoma of the humeri with pathologic fractures: A case report. World J Radiol 5: 345-348.

8. Mohan A, Jalgaonkar A, Briggs T (2011) Intraosseous xanthoma of the hand without an underlying lipid disorder. J hand surg 36: 520-522.

9. Yamamoto T, Kawamoto T, Marui T, Akisue T, Hitora T, et al. (2003) Multimodality imaging features of primary xanthoma of the calcaneus. Skeletal Radiol 32: 367-370.

10. Alden K, McCarthy E, Weber K (2008) Xanthoma of Bone: A Report of Three Cases and Review of the Literature. Iowa Orthop J 28: 58-64.

11. Kumar K, Matos Y, Thirkannad S (2014) Intraosseous xanthoma of the distal radius a report. Hand Surg 19: 223-226.

12. Bertoni F, Unni KK, McLeod RA, Sim FH (1988) Xanthoma of bone. Am J Clin Pathol 90: 377-384.

13. Shin WC, Moon NH, Suh KT (2016) Primary Intra-Osseous Xanthoma Involving the Proximal Femur in a Normolipidemic Patient: A Case Report. Hip Pelvis 28: 182-186.

14. Ayadi-Kaddour A, Mlika M, Marghli A, Kilani T, El Mezni F (2008) Xanthoma of the rib without hypolipoproteinemia. Resp Med 1: 40-42.

15. Torigoe T, Terakado A, Suehara Y, Kurosawa H (2008) Xanthoma of bone associated with lipoprotein lipase deficiency. Skeletal Radiol 37:12:1153-1156.

16. Asano K, Sato J, Matsuda N, Ohkuma H (2012) A rare case of primary bone xanthoma of the clivus. Brain Tumor Pathol 29: 123-128.

17. Harsanyi BB, Larsson A (1988) Xanthomatous lesions of the mandible: osseous expression of non-X histiocytosis and benign fibrous histiocytoma. Oral Surg Oral Med Oral Pathol 65: 551-566.

18. Dalinka MK, Turner ML, Thompson JJ, Lee RE (1982) Lipid granulomatosis of the ribs: focal Erdheim-Chester disease. Radiol 142: 297-299.

19. Kuroiwa T, Ohta T, Tsutsumi A (2000) Xanthoma of the temporal bone: Case report. Neurosurgery 46: 996-998.

20. Jackler RK, Brackmann DE (1987) Xanthoma of the temporal bone and skull base. Am J Otol 8:111-115.

21. Kinberg P (1998) Xanthoma of a calcaneus. J Foot Ankle Surg 37: 531-534.

22. Kapukaya A, Arslan H, Özkul E, Mizrak B (2011) Primary xanthofibroma in the calcaneus: a case report. Acta Orthop Traumatol Turc 45: 203-207.

23. Robertson DP, Langford LA, McCutcheon IE (1995) Primary xanthoma of thoracic spine presenting with myelopathy. Spine 20: 1933-1937. 